\title{
Enchancement of Toremifene Anti-Tumor Action by Metformin and Unusual Side Effect of Toremifene in Male Transgenic Mice with HER2-Positive Breast Tumor
}

\section{Authors}

Alexander N. Stukov', Mikhail A. Osipov'1, Tatjana Y. Semiglazova', Larisa V. Filatova', Valerij A. Alexandrov², 4 , Vladimir G. Bespalov², 4 , Alexander L. Semenov ${ }^{2,4}$, Margarita L. Tyndyk ${ }^{3}$, Maria N. Yurova ${ }^{3}$, Andrey V. Panchenko ${ }^{3}$, Denis A. Baranenko 4

\section{Affiliations}

1 Department of Innovative Methods of Therapeutic Oncology and Rehabilitation, N. N. Petrov National Medical Research Center of Oncology, St. Petersburg, Russia

2 Laboratory of Cancer Chemoprevention and Oncopharmacology, N. N. Petrov National Medical Research Center of Oncology, St. Petersburg, Russia

3 Laboratory of Carcinogenesis and Aging, N. N. Petrov National Medical Research Center of Oncology, St. Petersburg, Russia

4 International Research Centre "Biotechnologies of the Third Millennium”, ITMO University, St. Petersburg, Russia

\section{Key words}

toremifene, metformin, breast cancer, FVB/N HER-2/neu mice, hernia, antitumor effect

$$
\begin{array}{ll}
\text { received } & 13.02 .2019 \\
\text { accepted } & 09.04 .2019
\end{array}
$$

\section{Bibliography}

DOI https://doi.org/10.1055/a-0892-4118

Published online: 23.9 .2019

Drug Res 2019; 69: 683-687

(c) Georg Thieme Verlag KG Stuttgart · New York ISSN 2194-9379

\section{Correspondence}

Vladimir Bespalov

Laboratory of Cancer Chemoprevention and

Oncopharmacology,

N.N. Petrov National Medical Research Center of Oncology, 197758 St. Petersburg,

Russia

Tel.: + 7/921/930 6429,

bespalov_niio@mail.ru

\begin{abstract}
HER2-positive breast tumors are found in $25-30 \%$ of patients with breast cancer and are characterized by aggressive course and reduced sensitivity to both chemotherapy and hormone therapy. The aim of the work was to study the possibilities of enhancing the therapeutic effect of anti-estrogen drug toremifene by combining it with biguanide, metformin, on the HER2-positive breast cancer model in FVB/N HER-2/neu transgenic mouse. Male FBV/N mice with intramuscularly transplanted HER2-positive mammary gland tumor from a female mouse of the same strain have been given toremifene $(30 \mathrm{mg} /$ $\mathrm{kg}$, orally daily) or metformin ( $100 \mathrm{mg} / \mathrm{kg}$, orally daily) that had a moderate antitumor effect (decrease the area under the kinetic curve of tumor growth by 1.6 and 1.5 times, respectively, when compared with intact control). Co-administration of these drugs in the same doses had a more pronounced effect (the area under the kinetic curve of tumor growth decreased by 3.1 times compared to intact control; $p<0.05$ ). After 10 days, in group receiving toremifene all 10 mice developed inguinal-scrotal hernias, and in group that received toremifene plus metformin - only 5 of $10(p=0.0325)$. By the $15^{\text {th }}$ day after the start of treatment, the hernias was also determined in all mice treated with the combination of toremifene and metformin, but the size of the hernial sac was significantly smaller than in those receiving only toremifene $-537 \pm 96 \mathrm{~mm}^{3}$ and $1309 \pm 120 \mathrm{~mm}^{3}$, respectively $(p=0.0001)$. A possible explanation is the manifestation of collagen-degrading effect of toremifene.
\end{abstract}




\section{Introduction}

HER2-positive breast tumors are found in 25-30\% of patients with breast cancer and are characterized by aggressive course and reduced sensitivity to both chemotherapy and hormone therapy $[1,2]$. There is evidence that the use of anti-diabetic biguanide metformin can enhance the effectiveness of chemotherapy and hormone therapy of tumors, including the mammary gland $[3,4]$.

The aim of this study was to investigate the anti-tumor activity of anti-estrogen drug toremifene in transgenic HER-2/neu FVB/N mice with a HER2-positive breast tumors and to evaluate the modifying influence of metformin on the effect of toremifene.

\section{Materials and Methods}

\section{Animals}

In experiments, we used FVB/N strain mice, carrying erbB2 (HER2) gene, which are characterized by a high incidence of the development of spontaneous HER2-positive mammary adenocarcinomas (in females up to $100 \%$, in males - in rare cases) [5].

These FVB/N mice were obtained from the National Institute of Aging (Ancona, Italy) and are maintained as local breeding stock in vivarium of N.N. Petrov National Medical Research Center of Oncology (St. Petersburg, Russia). All animals were kept under standard conditions $\left(12 / 12 \mathrm{~h} \mathrm{light/dark} \mathrm{regimen} \mathrm{and} \mathrm{at} 21-23^{\circ} \mathrm{C}\right)$. They received standard pellet laboratory diet (PK-120; Laboratorkorm, Moscow, Russia) and tap water ad libitum.

\section{Drugs}

The following drugs were used in the experiments: toremifene (Fareston, Orion Corporation, Finland) and metformin (HEMOFARM A.D., Serbia).

\section{Experimental design}

Studies were conducted on 42 adult male mice of the $F V B / N$ strain weighing $22-25 \mathrm{~g}$. All mice were inoculated intramuscularly with a $20 \%$ suspension of tumor tissue taken from the female mouse of same strain with spontaneous breast cancer. On the $5^{\text {th }}$ day after tumor inoculation, the mice were randomized and drug treatment was started.

Group I $(n=12) \quad$ - Control,

Group II $(n=10) \quad$ - Toremifene $(60 \mathrm{mg} / \mathrm{kg}$ daily),

Group III ( $n=10) \quad$ - Metformin (200 mg/kg daily),

Group IV $(\mathrm{n}=10) \quad$ - Toremifene $(60 \mathrm{mg} / \mathrm{kg}$ daily $)$ + Metformin (200 mg/kg daily).

All drugs were given with drinking water, calculated on the basis of daily consumption of about $4 \mathrm{ml}$ per mouse. Drug solutions were prepared daily. The drugs were given to mice daily for 23 days until the end of the experiment.

\section{Quantitative evaluation of anti-tumor effect}

Antitumor activity was assessed by calculating the percentage of inhibition of tumor growth, as well as by the area under the kinetic curve of tumor growth and tumor growth index.
The percentage of inhibition of tumor growth (TI\%) was determined by the formula:

$\mathrm{TI} \%=\frac{\mathrm{V}_{\mathrm{C}}-\mathrm{V}_{\mathrm{T}}}{\mathrm{V}_{\mathrm{C}}} \times 100$

where $V_{C}$ is the average tumor volume in mice of the control group, and $V_{E}$ is the average tumor volume in mice of the experimental group receiving the drug.

The tumor volume was calculated using the modified ellipsoidal formula [6]:

$V=\frac{A \times B^{2}}{2}$

where $\mathrm{V}$ - tumor volume, $\mathrm{mm}^{3}$; $\mathrm{A}$ - the greatest longitudinal diameter (length), mm; $B$ - the greatest transverse diameter (width), mm.

The same formula was used to measure the volume of the hernial sac in mice with inguinal-scrotal hernias that complicated treatment with toremifene.

Due to intramuscular tumor inoculation, the volume of the whole thigh with the tumor was measured, therefore, to more accurately determine the actual volume of the tumor, the volume of the healthy contralateral thigh was subtracted from the obtained value.

The tumor growth index (TGI) was determined in percent by the formula:

$\mathrm{TGl} \%=\frac{\mathrm{S}_{\mathrm{E}}}{\mathrm{S}_{\mathrm{C}}} \times 100$

where $S_{E}$ is the area under the kinetic curve of tumor growth in the experimental group of mice, and $S_{C}$ is the area under the kinetic curve of tumor growth in mice of the control group. It is obvious that an TGI in the control will always be equal to $100 \%$, whereas in the experimental groups, with regression or slowing down of tumor growth, the TGI will be less than $100 \%$, and when stimulating tumor growth, it will be more than $100 \%$. It is important to note that the TGI is an integral criterion for the antitumor activity of the drug, which makes it possible to evaluate not only the degree of expression of the antitumor action, but also its duration.

The trapezoidal method was used to measure the area under the kinetic curve of tumor growth.

\section{Statistic analysis}

Statistical analysis was performed using programs GraphPad ${ }^{\circledR}$ Prism 6, SPSS ${ }^{\circledR}$ Statistics version 17.0. Student's t-test was used. $\mathrm{P}<0.05$ was considered statistically significant.

\section{Ethical approval}

All experimental procedure and also the design of these experiments was approved by the Ethics Committee of the N.N. Petrov National Medical Research Center of Oncology (St. Petersburg, Russia), following international guidelines for the care and use of animals. 


\section{Results}

Comparative results of the inhibitory effect (TI\%) of toremifene and metformin on the growth of an intramuscularly implanted HER2positive breast tumor ( $\triangleright$ Fig. $\mathbf{1}$ ) in male FVB/N mice are presented in $>$ Table 1 . The course administration of toremifene in the daily dose of $200 \mathrm{mg} / \mathrm{kg}$ had a pronounced antitumor effect. At 12-18 days tumor growth inhibition reached $54-81 \%$ and was statistically significant. Another drug, metformin, caused a slight but statistically significant inhibition of tumor growth by $12^{\text {th }}$ day. With the

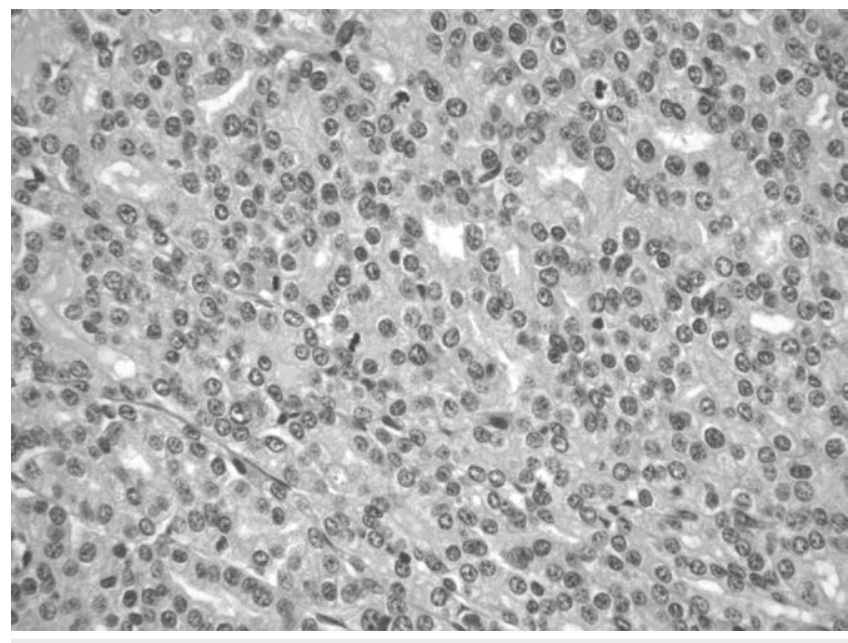

- Fig. 1 The histological picture of mammary tumor transplanted intramuscularly to male $\mathrm{FVB} / \mathrm{N}$ mouse from female mouse with HER2-positive spontaneous mammary adenocarcinoma. Hematoxylin-eosin. X 400. combination of toremifene with metformin, inhibition of tumor growth was more pronounced than with their separate use. In addition, this antitumor effect was significantly manifested during all days of treatment ( $\triangleright$ Table 1 ).

When evaluating the antitumor activity of the drugs with indicators ( $S$ - the area under the kinetic curve of tumor growth and TGI - tumor growth index), a significant effect was manifested only with the combined use of toremifene and metformin ( $\triangleright$ Table 2 ).

In the course of this experiment, from the 10th day after the start of toremifene administration (group II), all 10 mice developed inguinal-scrotal hernias ( $\triangleright$ Fig. 2), which, as was found in autopsy at the end of experiment, contained intestinal loops. Similar hernias were diagnosed in 5 of 10 mice treated with toremifene in combination with metformin (group IV). On the $15^{\text {th }}$ day after the start of the administration of toremifene, the hernial sacs were present in all mice of group IV, but their volumes were significantly smaller than in mice of group II ( $\triangleright$ Table 3 ). In groups 1 (control) and III (administration of metformin) no hernias were found in the course of experiment.

\section{Discussion}

Toremifene as an antiestrogen drug is widely used in hormone therapy of estrogen-positive breast cancer, not only in women, but also in men [7]. The effectiveness of anti-estrogen drugs in HER2-positive breast tumors is markedly lower, even with estrogen-receptor-positive tumors [2]. In our experiments, toremifene produced a marked inhibitory activity on tumor growth of HER2-positive breast cancer in FVB/N mice transgenic for the HER2 proto-oncogene. In particular, it was established that the content of estrogen

- Table 1 The influence of toremifene and metformin on the growth HER2-positive mammary gland tumors in male FVB/N mice.

\begin{tabular}{|c|c|c|c|c|c|}
\hline \multirow[t]{3}{*}{ No. group, treatment } & \multicolumn{5}{|c|}{ Tumor volume, $\mathrm{mm}^{3}(\mathrm{M} \pm \mathrm{m})$; TI\% to control } \\
\hline & \multicolumn{5}{|c|}{ Days after tumor inoculation } \\
\hline & 12 & 15 & 18 & 20 & 23 \\
\hline I. Control $(n=12)$ & $52 \pm 8$ & $108 \pm 17$ & $262 \pm 52$ & $619 \pm 167$ & $885 \pm 190$ \\
\hline \multirow[t]{3}{*}{ II. Toremifene $(n=10)$} & $10 \pm 5$ & $31 \pm 10$ & $119 \pm 30$ & $387 \pm 202$ & $677 \pm 286$ \\
\hline & $81 \%$ & $71 \%$ & $54 \%$ & $37 \%$ & $24 \%$ \\
\hline & $\mathrm{p}=0.0007$ & $p=0.0021$ & $p=0.0377$ & $p=0.2646$ & $p=0.4753$ \\
\hline \multirow[t]{3}{*}{ III. Metformin $(n=10)$} & $29 \pm 4$ & $79 \pm 10$ & $141 \pm 29$ & $452 \pm 106$ & $566 \pm 151$ \\
\hline & $44 \%$ & $27 \%$ & $46 \%$ & $27 \%$ & $36 \%$ \\
\hline & $p=0,0231$ & $p=0,1669$ & $p=0,0637$ & $p=0,4046$ & $p=0,1991$ \\
\hline \multirow{3}{*}{$\begin{array}{l}\text { IV. Toremifene + metformin } \\
(\mathrm{n}=10)\end{array}$} & $3,5 \pm 3,5$ & $26 \pm 8$ & $96 \pm 22$ & $228 \pm 44$ & $250 \pm 55$ \\
\hline & $93 \%$ & $76 \%$ & $63 \%$ & $64 \%$ & $72 \%$ \\
\hline & $\mathrm{p}<0,0001$ & $p=0,0009$ & $p=0,0142$ & $p=0,0495$ & $p=0,0064$ \\
\hline
\end{tabular}

- Table 2 Antitumor activity of toremifene and metformin on the model of HER2-positive mammary gland tumors in male FVB/N mice, according estimate of the effect on the area under the kinetic curve of tumor growth (S) and tumor growth index (TGI).

\begin{tabular}{|l|l|l|l|l|}
\hline No. group, treatment & Number of mice & S & TGI & P in comparison with group I \\
\hline I. Control & 12 & $3932 \pm 896$ & $100 \%$ & \\
\hline II. Toremifene & 10 & $2388 \pm 1046$ & $59 \%$ & $>0.05$ \\
\hline III. Metformin & 10 & $2612 \pm 570$ & $66 \%$ & $>0.05$ \\
\hline IV. Toremifene + metformin & 10 & $1268 \pm 292$ & $32 \%$ & $<0.05$ \\
\hline
\end{tabular}




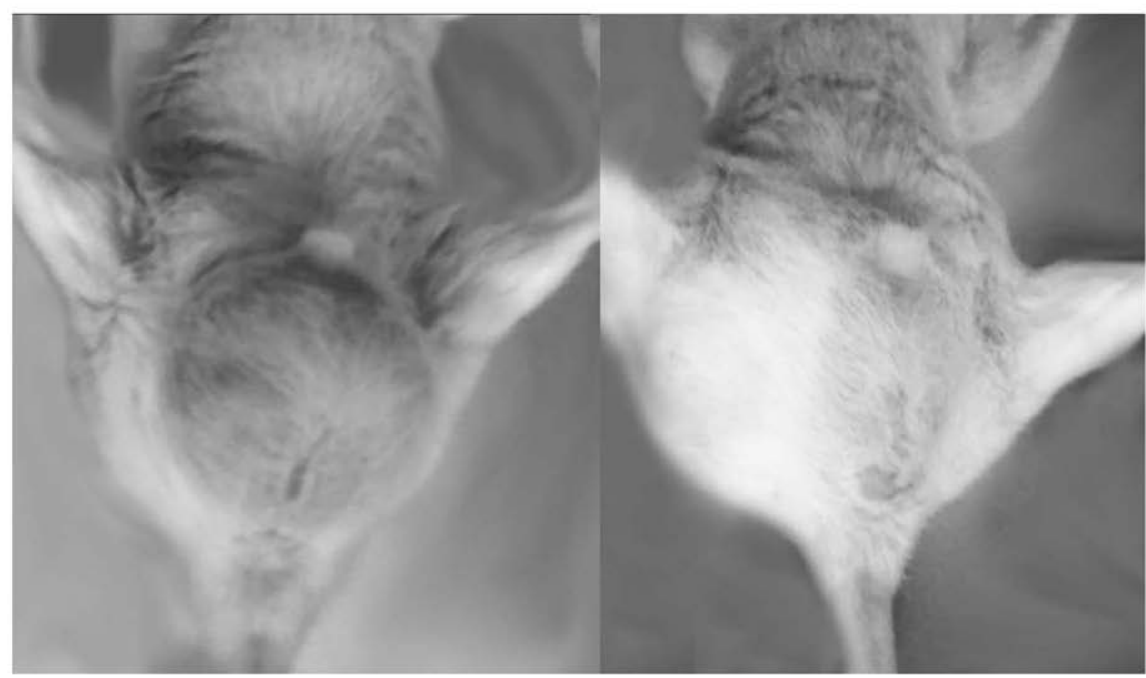

- Fig. 2 An inguinal-scrotal hernia in a male FVB/N mouse (left) that developed on the 10 th day after the administration of toremifene $(60 \mathrm{mg} / \mathrm{kg}$ orally daily). On the right - the mouse from the control group.

> Table 3 Influence of toremifene and metformin on the volumes of hernia sac inguinal-scrotal hernias in male FVB/N mice

\begin{tabular}{|c|c|c|c|c|}
\hline No. group, treatment & Number of mice & Volume of hernia sac, $\mathrm{mm}^{3}$ & $\begin{array}{l}\text { \%\% in comparison } \\
\text { with group II }\end{array}$ & $\begin{array}{l}\text { pin comparison } \\
\text { with group II }\end{array}$ \\
\hline I. Control & 12 & $0 \pm 0 \mathrm{~mm}^{3}$ & 0 & $<0.0001$ \\
\hline II. Toremifene & 10 & $1309 \pm 120 \mathrm{~mm}^{3}$ & 100 & \\
\hline III. Metformin & 10 & $0 \pm 0 \mathrm{~mm}^{3}$ & 0 & $<0.0001$ \\
\hline IV. Toremifene + metformin & 10 & $573 \pm 96 \mathrm{~mm}^{3}$ & 44 & 0.0001 \\
\hline
\end{tabular}

receptors in these tumors does not exceed $10 \mathrm{fM} / \mathrm{mg}$ protein, and the content of progesterone receptors was below this level [8]. In our experiments, metformin had a slight inhibitory effect on the growth of HER2-positive tumors in mice. The combination of toremifene with metformin contributed to the mutual enhancement of their antitumor action.

Toremifene is one of non-steroidal selective estrogen receptor modulators (SERMs), which are both antagonists and estrogen receptor agonists. SERMs have an anti-estrogenic effect mainly on the mammary gland, and at the same time, its estrogenic effect can occur to other organs such as bones, liver and uterus [9]. In clinical use, torimefene causes numerous side effects, the most frequent of which are hot flashes (20\%), increased sweating (14\%), nausea ( $8 \%$ ), dizziness (4\%), peripheral edema (3\%) [10]. In our experiments, an unusual side effect of toremifene in the form of an inguinal hernia repair was established for the first time. All mice of the $\mathrm{FVB} / \mathrm{N}$ male strain, after 10 days of daily oral administration of toremifene in a dose of $60 \mathrm{mg} / \mathrm{kg}$, developed significant inguinalscrotal hernia. The administration of metformin simultaneously with toremifene slowed down hernia development.

A possible explanation for the occurrence of inguinal-scrotal hernias in $\mathrm{FVB} / \mathrm{N}$ male mice under the influence of the antiestrogen toremifene is its estrogen-like side effect on connective tissue. According to S. Jackson, et al. [11], estrogen along with the stimula- tion of the formation of collagen in the connective tissue can cause its degradation. There is evidence of pluripotent effect of estrogen on collagen metabolism in the pelvic fascia, which is associated with both an increase in its synthesis and degradation [11].

\section{Acknowledgement}

This work was financially supported by the Ministry of Science and Higher Education of Russian Federation, Grant RFMEFI58117X0020.

\section{Conflict of Interest}

The authors declare that there is no conflict of interest.

\section{References}

[1] Muss HB, Thor AD, Berry DA et al. ErbB2 expression and response to adjuvant therapy in women with node-positive breast cancer. N Engl J Med 1994; 330: 1260-1266

[2] Stål O, Borg A, Fernö M et al. South Sweden Breast Cancer Group Southeast Sweden Breast Cancer Group 
[3] ErbB2 status and the benefit from two or five years of adjuvant tamoxifen in postmenopausal early stage breast cancer. Ann Oncol 2000; $11: 1545-1550$

[4] Anisimov VN. Metformin for cancer and aging prevention: Is it a time to make the long story short? Oncotarget 2015; 6: 398-407

[5] Osipov MA, Semiglazova TYu, Krivorotko PV et al. Metformin in the treatment of breast cancer. Malignant tumors 2017; 2: 76-82. in Russian

[6] Tyndyk ML, Popovich IG, Anikin IV et al. The effect of SSH \& H on the lifespan and development of spontaneous tumors in transgenic HER2/ neu mice. Vopr. Oncology 2012; 2: 243-247. in Russian

[7] Tomayko MM, Reynolds CP. Determination of subcutaneous tumor size in athymic (nude) mice. Cancer Chemother Pharmacol 1989; 24: 148-154. doi:10.1007/BF00300234
[8] Vogel CL, Johnston MA, Capers C et al. Toremifene for breast cancer: A review of 20 years of data. Clinical breast cancer 2014; 14: 1-9

[9] Bershtein LM, Alimova IN, Tsyrlina EV et al. Breast tumors in transgenic HER-2 / NEU mice are characterized by a low content of estrogen receptor alpha and the absence of progesterone receptors. Bull Exper Biology. Medicine 2003; 135: 680-682. in Russian

[10] Selective Estrogen Receptor Modulators. Advances in Research and Application: 2013 Edition: ScholarlyBrief. ScholarlyEditions 2013; 51:

[11] Rosenthal L, Burchum J. Lehne's Pharmacotherapeutics for Advanced Practice Providers. Elsevier Health Sciences 2017; 931p

[12] Jackson S, James M, Abrams P. The effect of oestradiol on vaginal collagen metabolism in postmenopausal women with genuine stress incontinence. Br J Obstet Gyn 2002; 109: 339-344 